\title{
1 The Ancient Britons: Groundwater fauna survived extreme climate 2 changes over tens of millions of years across NW Europe
}

3 Caitríona E. McInerney ${ }^{1,2,3}$, Louise Maurice ${ }^{4}$, Anne L. Robertson ${ }^{5}$, Lee R.F.D. Knight ${ }^{6}$, Jörg 4 Arnscheidt $^{1}$, Chris Venditti ${ }^{3,7}$, James S.G. Dooley ${ }^{2}$, Thomas Mathers ${ }^{3}$, Severine Matthijs ${ }^{8,9}$,

5 Karin Erikkson ${ }^{1}$, Graham S. Proudlove ${ }^{10}$ \& Bernd Hänfling ${ }^{3 *}$

*Corresponding author: b.haenfling@hull.ac.uk

Keywords: Phylogeography, Ancestral state reconstruction, Bayesian dating analysis, cave, subterranean 


\section{Abstract}

34 Global climate changes during the Cenozoic (65.5 - $0 \mathrm{Ma}$ ) caused major biological range 35 shifts and extinctions. In Northern Europe, for example, a pattern of few endemics and the 36 dominance of wide-ranging species is thought to have been determined by the Pleistocene 37 (2.59 - $0.01 \mathrm{Ma})$ glaciations. This study, in contrast, reveals an ancient subsurface fauna 38 endemic to Britain and Ireland. Using a Bayesian phylogenetic approach we found that two 39 species of stygobitic invertebrates (genus Niphargus) have not only survived the entire 40 Pleistocene in refugia but have persisted for at least 19.5 million years. Other Niphargus 41 species form distinct cryptic taxa that diverged from their nearest continental relative between 425.6 and 1.0 Ma. The study also reveals an unusual biogeographical pattern in the Niphargus 43 genus. It originated in Northwest Europe $\sim 88 \mathrm{Ma}$ and underwent a gradual range expansion. 44 Phylogenetic diversity and species age are highest in Northwest Europe suggesting resilience 45 to extreme climate change, and strongly contrasting the patterns seen in surface fauna. 46 However, species diversity is highest in Southeast Europe indicating that once the genus 47 spread to these areas ( $25 \mathrm{Ma})$, geomorphological and climatic conditions enabled much 48 higher diversification. Our study highlights that groundwater ecosystems provide an 49 important contribution to biodiversity and offer insight into the interactions between 50 biological and climatic processes. 


\section{INTRODUCTION}

Global climate has changed significantly throughout the Cenozoic (65.5- $0 \mathrm{Ma}$ ) with glacial cycles during the Miocene, Pliocene and Pleistocene (Louwye et al. 2008; Zachos et al. 2001a; Zachos et al. 2008). Precipitation also fluctuated from extended arid (13.2 - 11.5 Ma) to very wet conditions (10.2-9.8 Ma; Bohme et al. 2008). Fauna, for example ectothermic vertebrates and freshwater Crustacea, experienced major range shifts or extinctions, and ecosystems were dramatically modified (Bohme 2003, Klaus and Grosse 2010). During the Pleistocene glaciations (2.59 - $0.01 \mathrm{Ma}$ ), large areas of the northern hemisphere were covered by glaciers or permafrost and were uninhabitable (reviewed in Provan \& Bennett 2008), with particularly marked biogeographic impact in northern Europe.

Britain and Ireland are a prime example illustrating this ecological impact, with repeated covering by glaciers and permafrost greatly limiting the persistence of terrestrial species. These islands are likely to have been isolated during interglacials, at least since the formation of the English Channel $\sim 0.45 \mathrm{Ma}$ (Gupta et al. 2007), preventing dispersal of terrestrial fauna from the continent. Strong palaeontological and genetic evidence indicates that the majority of the current fauna of Britain and Ireland arrived from mainland Europe following the Pleistocene glaciations, dispersing across a land bridge with continental Europe during the short period after ice retreat and before the bridge was submerged by rising sea levels (Hewitt 2004; Yalden 1982). Consequently Britain and Ireland have always been thought to have limited endemic biodiversity. However, the biodiversity of groundwater ecosystems may challenge this orthodoxy, with evidence from North America (Holsinger et al. 1983) and Iceland (Kornobis et al. 2010), suggesting that groundwater ecosystems may occur under glaciated areas. Moreover species are present in formerly glaciated areas, indicating that they must either have survived in refugia or dispersed there since glaciations (Galassi et al. 2009; Martin et al. 2009). As with recent advances in our understanding of deep ocean vent ecosystems (Dubilier et al. 2008; Lopez-Garcia et al. 2003; Van Dover et al. 2002), groundwater ecosystems may offer novel insights into fundamental ecological and evolutionary processes. In this study we use a Bayesian phylogenetic approach, which shows that groundwater fauna must have persisted through glacial periods in Britain and Ireland within refugia. Furthermore, we show how groundwater ecosystems may have developed across Europe in response to changing climatic and geomorphological conditions. Finally we demonstrate that the biogeographical pattern of diversity across Europe is unexpected, with increasing phylogenetic diversity at higher latitudes. 
86 Our study focuses on amphipod crustacea, which are a major component of subterranean ecosystems, and offer a tractable model for investigating ecological and evolutionary processes within this challenging environment. The largest genus among them is Niphargus (Amphipoda: Niphargidae) with over 300 described species distributed across most of Europe (Vainola et al. 2008). Niphargus are stygobites (obligate groundwater inhabitants), 0.3-3.0 $\mathrm{cm}$ in length, which are adapted to live in subterranean environments. They are blind, lack pigmentation and have elongated appendages (Figure 2a). Previous phylogeographic studies of Niphargus have demonstrated high levels of endemism and cryptic diversity at small geographic scales (Fišer et al. 2008; Trontelj et al. 2009), suggesting limited dispersal and long-term persistence of local populations, as well as morphological convergence for adaptations to the subterranean environment (Trontelj et al. 2012). Only six taxa of Niphargus are currently known from Britain and Ireland (Robertson et al. 2009). Here we show that two species endemic to Britain and Ireland ( $N$. glenniei and N. irlandicus) are far older than previously thought, suggesting persistence through extreme climatic and geomorpological changes over at least 19 million years. Furthermore, those species thought to have been wide ranging European species (N. aquilex, N. fontanus, N. kochianus) are in fact also ancient British endemics.

\section{MATERIAL AND METHODS}

\section{Sampling}

A modified Cvetkov net sampler, notenboom sampler, or baited traps were used to collect samples from boreholes, springs and wells. 454 Niphargus specimens were preserved in $>70 \%$ ethanol (Figure 1, Table S1), comprising samples from 63 populations (222 individuals) in Britain and Ireland including five of the six species present. We were unable to obtain sufficient samples for DNA extraction of the rare N. wexfordensis. Additionally, 224 individuals from 47 populations and 5 species were collected from Belgium, the Netherlands, Germany and France (Figure 1, Table S1) including all species known to cooccur in Britain and continental Europe (N. aquilex, N. fontanus, N. kochianus). Furthermore, samples were obtained from two species which occur in the vicinity of Britain located in France, but for which no DNA sequence data existed ( $N$. pachypus, 1 population, 2 individuals; $N$. forelli, 2 populations, 4 individuals). Samples from published data sets (see below) covered largely the central and south-eastern part of the distribution and included data of 185 populations from 74 described species (Figure 1, Table S1). 


\section{De novo sequencing and data sets for phylogenetic analysis}

Genetic variation of Niphargus was assessed at two mitochondrial genes, cytochrome oxidase subunit I (COI) and 16s rRNA (16S) and the nuclear small subunit 28s rRNA (28S; for details see Supplementary materials). Our analysis combined these new DNA sequence data with all published Niphargus sequence data for 28S, COI and 16S available on GenBank on June 1st, 2012 (Fišer et al. 2008; Flot 2010; Flot et al. 2010; Hänfling et al. 2008; Hartke et al. 2011; Lefébure et al. 2006; Lefébure et al. 2007; Trontelj et al. 2009). Also included were published sequence data of the mitochondrial 12s rRNA region (12S) and the large subunit 18s rRNA (18S) for the taxa covered in the combined data set. In total, data were included from 78 described species, and several putative cryptic species, from 170 locations across the genus' European range (Figure 1, Tables S1, S3). This includedeight of the nine species (the ninth, N. boulangei, was too rare) that occur within $200 \mathrm{~km}$ of Britain (Table S1). The combined data set provided phylogeographic information (more than 10 populations) for 8 of the 78 described species (Table S2, N. aquilex, N. fontanus, $N$. glenniei, N. kochianus, $N$. irlandicus, N. rhenorhodanensis, N. virei, N. schellenbergi). A further 11 species were covered by more than 1 specimen from 1 - 3 locations.

A total of 36 taxa from 9 amphipod families were used as outgroups to root the Niphargus phylogeny, and provide calibration points for a molecular dating analysis (see Table S4), The outgroup taxa include previously identified sister groups to Niphargidae (Englisch et al. 2003, Fiser et al. 2008) and representatives of clades from a dated phylogeny of gammarid amphipods (Hou et al. 2011). We used the genes 28S, COI, 18S and elongation factor 1 alpha (EF-1a). The alignment of COI and EF-1a sequences was carried out using MUSCLE (Edgar 2004) in combination with MEGA version 5.05 (Tamura et al. 2011). Ribosomal genes were aligned with the software MAFFT version 6 (Katoh et al. 2002) using the alignment strategies Q-INS-i or E-INS-i.

\section{Delineation of OTUs, multi-locus alignments and phylogenies}

Cryptic diversity and taxonomic misclassification are common in Niphargus. We therefore used a DNA barcoding approach based on the two genes with the largest coverage (COI and $28 \mathrm{~S}$ ) to identify cryptic lineages within species and to delineate operational taxonomic units (OTUs) with independent evolutionary histories (for details see Supplementary materials). Many of these OTU's are likely to fulfil the criteria for separate species depending on the definition applied, but a discussion of species status is outside the scope of this paper. A 
150 multi-locus alignment was created using representatives of OTU's of Niphargus and selected outgroups. One representative of each OTU was chosen at random for inclusion in the supermatrix (Table S1). Amphipod outgroups included three representatives selected for each of the 4 Gammarus freshwater clades, 6 representatives of the marine Gammarus group, 3 representatives of the Baikalian Gammarids and all outgroups used in Hou et al. (2011), providing 13 time-calibrated nodes. For each gene, all sequences of the selected taxa were aligned. Phylogenetic analysis of the multi-gene matrix was carried out using Bayesian analysis as implemented in MrBayes v3.2 (Ronquist et al. 2012). Genes were used as partitions and model parameters between partitions were unlinked. Two independent Markov chain Monte-Carlo (MCMC) chains were run for 10,000,000 iterations each, sampling every 1,000 iterations. The first $25 \%$ of each run was discarded as burnin with the remaining samples pooled and used to create a maximum clade credibility tree.

\section{Molecular dating using a Bayesian analysis}

BEAST (Bayesian Evolutionary Analysis Sampling Trees) version 1.7.4 (Drummond et al. 2012) was used to generate an ultrametric phylogeny and estimate the time of the most recent common ancestor (TMRCA) for each node using a Bayesian MCMC analysis. Tree topology was constrained to that obtained from the MrBayes phylogenetic analysis. Genes were used as partitions and substitution rates and clocks were unlinked in the analysis. An uncorrelated lognormal relaxed clock (Drummond et al. 2006) and a Yule speciation prior were used. A time calibrated phylogeny of the amphipod group Gammaridae (Hou et al. 2011) was used to provide 11 external calibration points (for details see Supplementary materials).

\section{Ancestral longitude and latitude reconstructions}

We used the Bayesian MCMC phylogenetic ancestral state reconstruction method introduced by Organ et al. (2007) to infer the geographical location of the MRCA for each node. The method was chosen because of its superior performance with phylogenetic trees that span millions of years (Montgomery et al. 2010). Similar methods have been used to infer ancestral longitudes and latitudes in a phylogenetic context (Bouckaert et al. 2012; Lemey et al. 2009). With exact geographical ranges mostly unknown it was not possible to calculate range centroids. The range size of most Niphargus is small, however, usually $<100 \mathrm{~km}$ in diameter. (Trontelj et al. 2009). The few taxa with a larger range such as $N$. virei and $N$. rhenorhodanensis consist of a number of cryptic taxa or distinct phylogeographic units with a 
181

much smaller range (Lefébure et al. 2006; Lefébure et al. 2007). This cryptic diversity is reflected in the OTUs used for the phylogenetic analysis. We therefore used the geographical coordinate of the individual chosen at random for the phylogenetic analysis as a proxy for the taxon's geographic location. We estimated a phylogenetic model of evolution for the Niphargus ingroup species where longitude and latitude were correlated using the computer program BayesTraits (Pagel et al. 2004). We ran the MCMC chain for one million iterations after apparent convergence sampling every 1,000 iterations from the chain and repeated the analysis multiple times. We also simultaneously estimated the phylogenetic signal parameter $\lambda$ (Pagel 1999). The parameter $\lambda$ varies between 0 and 1 , where 1 is interpreted as having the traits covary and zero means that the traits evolve independently of the phylogenetic relationships among species. Repeated analyses produced almost identical results, thus we provide results from a single chain only.

\section{Geographic variation in species diversity and diversification rates}

To quantify geographic patterns in the distribution of species, we used the checklist of Niphargus species publically available at http://niphargus.info/ (Cene Fišer, unpublished) and created presence/absence data for 9 geographic regions in Europe based on the biogeographic areas for European freshwater fauna described in Illies (1978). Some regions were pooled to reduce the effect of uncertainty in geographic distribution (see Table S1). Species richness and species richness standardised for area (species/100,000 $\mathrm{km}^{2}$ ) were calculated using area sizes from Hof et al. (2008). To test the hypothesis that species richness differed between the Western and the Eastern parts of the genus' distribution, biogeographic areas were grouped into West (Spain, British Isles, West Europe, Central Europe) or East (Italy, Balkans, PontoDanubian, Caucasus) and their mean species richness standardised for area compared using a Mann-Whitney U-test. We tested a geographic association of net-diversification rates accounting for shared ancestry as implied by our phylogeny. We implemented the 'simple test' described in Freckleton et al. (2008) to relate traits to net-speciation rate (as determined by root-to-tip node count) in a Bayesian analytical framework. In order to explicitly test a hypothesis of an increase in diversification rate towards the south-east, a spatial rotation was applied to the coordinates of the samples to produce axes aligned at 15 degrees from the original. The most north-westerly point within the dataset was used as a new origin for the $\mathrm{x}$ axis, and the distance between this origin and the other points along the axis was calculated to provide a measure of how far towards the southeast the each point lies. 


\section{RESULTS}

215

216

217

218

219

220

221

222

223

224

225

226

227

228

229

230

231

232

233

234

235

236

237

238

239

240

241

\section{Data overview}

In all 43 OTUs were identified based on the COI phylogeny including 19 previously described cryptic lineages and 9 newly identified OTUs (Figure S1). Eighty nine additional taxa were identified based on 28S sequences (Figure S2), most corresponding to described or previously reported cryptic species (Table S1). In total 132 OTUs were identified using DNA barcoding.

\section{Phylogenetic analysis}

Results from multigene phylogenies revealed that the island endemics, $N$. irlandicus and $N$. glenniei are sister taxa with no close relative in Continental Europe (Figure 2b, S1, S2). The remaining taxa fall into eleven divergent lineages. These show strong geographical associations demonstrating poor dispersal within the genus even at large scales and over long geological time scales (Figure 2c). Phylogenetic diversity of Niphargus in Ireland and Britain is very high given the low species diversity, with the six species representing four different major lineages. This high phylogenetic diversity is apparent in other northern parts of the genus distribution. Nine lineages occur north-west of the Alps, with only three lineages south-east of the Alps. The overall pattern is a decrease in phylogenetic diversity from northwest to southeast Europe.

Outgroup rooting revealed that the split between the $N$. irlandicus / N. glenniei group and the remaining species represents the most basal node in the phylogenetic tree (Figure 2b). Our results also show that the three species which co-occur in Britain and Continental Europe $(N$. aquilex, $N$. fontanus and $N$. kochianus) are in fact phylogenetic clades comprising 7, 4 and 4 highly divergent lineages respectively which met our criteria for OTU's (Figure 3a-d) Each complex contains endemic British OTU's. (Table 1). Three cryptic N. aquilex OTU's occur in Britain, two of which ( $N$. aquilex $A 1$ and $B$ ) have not been found in continental Europe and have evolved independently. The two other non-endemic British taxa N. kochianus and N. fontanus are also represented by genetically distinct British lineages that diverged from their continental European counterparts after separate isolation events. 
242 Whilst it is possible that there are additional OTUs not included in this analysis that are more 243 closely related to the UK OTUs, this is unlikely because of the comprehensive sampling 244 coverage in this study. Importantly we have (i) sampled 8 of the 9 species which occur in the 245 vicinity of $200 \mathrm{~km}$ from the British coast line. The only unsampled species from this group 246 (N. boulangei) is extremely rare and has only been described once from a single location; (ii) 247 all taxa occurring in Britain and Ireland have been sampled on a phylogeographic scale 248 covering most of their range; (iii) there has been extensive groundwater sampling in France 249 and Belgium, for example during the recent large EU funded Pascalis project (Dole-Olivier et 250 al. 2009). Therefore it is unlikely that there are additional undescribed Niphargus species in 251 the countries adjacent to the UK; (iv) long distance colonisation is extremely unlikely and 252 any additional undescribed species in more distant areas are unlikely to impact on the conclusions of this study. Furthermore, our findings are strengthened by the fact that we found a consistent pattern across all taxa. Bayesian dating analysis and ancestral longitude and latitude reconstructions of MRCAs

Estimates of divergence times for all nodes separating British and Irish taxa from their nearest relatives are shown in Table 1. The ultrametric tree generated from the analysis is shown in Figure 4a. The Bayesian dating analysis and ancestral state reconstruction of the geographic origin of the MRCA for each node revealed that the MRCA of the two endemic British taxa was estimated to have lived in south-west England around 19.5 million years ago (95\% HDP, 38.1 - 6.7Ma, Figure 4b, 4f, Table 1). Thus, Niphargus must have persisted in Britain and Ireland at least since the Miocene making it the oldest known fauna by at least two orders of magnitude. This common ancestor must have existed at a time when the British and Irish landmasses were joined. The two sister taxa may subsequently have become isolated during an Oligocene marine inundation of the Irish Sea Basin (Cope 1997).

Three cryptic N. aquilex taxa occur in Britain, two of which (N. aquilex Al and B) have not 267 been found in continental Europe and have evolved independently for 1.0 and 5.6 Ma 268 respectively (Table 1). The two other non-endemic British taxa N. kochianus and N. fontanus 269 are also represented by genetically distinct British lineages that diverged from their 270 continental European counterparts after separate isolation events 2.9 and 0.8 Ma respectively. 271 Collectively these data suggest that almost the entire Niphargus fauna of Britain and Ireland 272 is comprised of endemic lineages of Miocene or late-Pliocene to mid-Pleistocene origin. 273 Final isolation of these taxa from continental populations may have resulted from the 274 formation of the English Channel at $0.45 \mathrm{Ma}$ (Gupta et al. 2007). 
275 The geographic distribution of MRCAs for nodes of different ages identified central France

276 in northwestern Europe as the origin of the Niphargus genus in the late Cretaceous (88 Ma).

277 From there the ancestral locations move with decreasing node age towards the southeast 278 (Figure $4 b)$.

\section{Geographic variation in species diversity and diversification rates}

280

281

282

283

Investigation of the geographic variation in species diversity revealed that the number of Niphargus species varies greatly across different geographic areas from 1 species in Spain to 136 in the Balkans (Figure S5). In contrast to phylogenetic diversity the species richness of the Western region is significantly lower than that of the Eastern region $(P<0.05)$. Investigation of the geographic variation in diversification rates shows that the number of nodes along each root-to-tip path in the Niphargus species level phylogeny correlates significantly with distance towards the southeast (correlation coefficient [SD] $=0.18$ [0.014], $\log$ Bayes Factor $=9.8$ ). A log Bayes Factor value of between 6 and 10 provides strong support for the hypothesis tested. Net-diversification rate in Niphargus therefore increases in a south-easterly direction.

\section{DISCUSSION}

\section{Phylogenetic evidence for long-term persistence of Niphargus in NW Europe}

Paleontological and genetic evidence suggests that the majority of surface fauna that currently live in Britain and Ireland originated from late Pleistocene/Holocene dispersal from Continental Europe (Hewitt 2004; Wheeler 1977; Yalden 1982). Endemic fauna are therefore rare (Pimm et al. 1995), and are restricted to a few surface invertebrate and vertebrate subspecies (e.g. the Irish hare, Reid 2011); and the Shelly freshwater whitefish, Kottelat \& Freyhof 2007; and the avian Scottish crossbill, which is sometimes considered a species, Summers et al. 2007, see Table S7 for more examples). Critically these fauna have only been present for a few tens of thousands of years. In contrast our data indicate that groundwater contains by far the oldest endemic fauna, which have persisted for millions of years and represent a significant contribution to biodiversity.

Furthermore, this ancient groundwater fauna has survived the extreme geological and climate changes that have occurred over the past 20 million years. Groundwater temperatures are 
305 influenced by air temperature (Figuera et al. 2011) and can range from 0 and $6^{\circ} \mathrm{C}$ in glacial and periglacial climates (Parsons 1970; Williams 1970) to $>25^{\circ} \mathrm{C}$ in areas with warm

307

308

309

310

311

312

313

314

315

316 climates (Eberhard et al. 2009; Weyhenmeyer et al. 2000). Niphargids must therefore have survived a wide range of groundwater temperature conditions as climate changed between glacial and warm conditions. However, temperature and chemistry change much more slowly in groundwater than surface waters, and hence groundwaters are buffered from temperature extremes and rapid hydrological and biological change (MacDonald et al. 2012), and the relative stability of the subsurface environment may explain the persistence of groundwater invertebrates through changing climates. N. glenniei and $N$. irlandicus persisted in NW Europe throughout the Miocene surviving both glacial and extreme wet periods (Zachos et al. 2001a; Zachos et al. 2001b) which were associated with range shifts and local extinctions in other fauna (Zachos et al. 2001a; Zachos et al. 2008). Together with N. aquilex $B$ they also persisted in Britain throughout the Pliocene when temperatures and sea levels were higher than today (Dwyer \& Chandler 2009), and groundwaters would have been substantially warmer than they are now.

All the Niphargus lineages in Britain and Ireland have persisted throughout the multiple glaciations of the Quaternary. Our findings are congruent with those of Kornobis et al. (2010) who presented molecular evidence showing that the endemic subterranean amphipod Crangonyx islandicus has been present in Iceland for around 5 million years, surviving repeated glaciations. On the basis of the molecular analysis and the species distribution, Kornobis et al. (2010) suggest that Crangonyx islandicus may have survived in geothermally heated groundwaters associated with volcanic fissures. Our data demonstrate that some Niphargus populations have been resilient to climate changes that occur above ground in a region that is much less geothermally active. This suggests that groundwater ecosystems in general may have mechanisms that reduce the impacts of surface climate change, but our current understanding of these mechanisms is limited. During glaciations, groundwater taxa may have survived in caves or aquifers that were actively recharged by warm-based glaciers or pro-glacial rivers. Groundwater recharge from glaciers is well documented (Boulton et al. 1995; Hutchinson \& Thomasbetts 1990), and provides a source of oxygen and nutrients. However, these groundwaters would have been cooler than today and therefore surviving species must be resilient to these long term variations in groundwater temperatures. Geothermal heating may have maintained some groundwaters at higher temperatures during glacial periods. For example it has been suggested that areas of southwest England remained 
338 permafrost free in the last glaciation due to a high heat-flux (Hutchinson \& Thomasbetts 339 1990) and there are small geothermal heat anomalies $\left(\sim 2\right.$ to $\left.6^{\circ} \mathrm{C}\right)$ within $100 \mathrm{~m}$ of the surface 340 in southern and eastern England (Busby et al. 2011). However, there is little relation between 341 modern day distributions of Niphargus in the British Isles and geothermally heated waters. 342 For example, Niphargus are not recorded in Derbyshire in Northern England where there are 343 extensive geothermal springs and suitable geological habitats for invertebrates, and are 344 present in areas of southern England where there is no evidence of geothermal warming of 345 groundwater. Given the poor dispersal capabilities of Niphargus it therefore seems unlikely 346 that geothermal heating of groundwater was the only factor enabling their survival during 347 glacial periods. A geothermal gradient of about $1{ }^{\circ} \mathrm{C}$ per 20 to $40 \mathrm{~m}$ (Anderson 2005) results 348 in warmer waters at depth, which may have provided some protection against cold 349 groundwaters if Niphargids were able to migrate to warmer, deeper waters. However, 350 permeability and fracturing generally decrease substantially with depth (Jiang et al. 2010; 351 Williams A et al. 2006), resulting in limited groundwater circulation and low oxygen, and 352 therefore the deep groundwater environment $(>100 \mathrm{~m})$ may not always provide a suitable 353 habitat for invertebrates. Overall it seems probable that surviving Niphargus species have 354 some mechanism of adapting to changing groundwater temperatures. Modern day occurrence 355 of groundwater crustacea in sub-glacial refugia has been documented in Castleguard Cave, 356 Canada, ca. $500 \mathrm{~km}$ north of the glacial limit, where groundwater temperatures are around $3572{ }^{\circ} \mathrm{C}$ (Holsinger et al. 1983) and in lava caves beneath ice in Iceland (Kornobis et al. 2010). 358 Nevertheless, other evidence indicates that the Pleistocene had a considerable negative 359 impact on the distribution and survival of Niphargus. The British Niphargus species (Figure 360 4) and $N$. virei in France (Foulquier et al. 2008) are largely found to the south of the maximum extent of the Anglian and Devensian glaciers, and species diversity in northwestern Europe is relatively low, suggesting that some populations were eradicated during glacial or periglacial conditions.

\section{Geographic origin of Niphargus and spread during the Cenozoic}

365 The geographic distribution of MRCAs for nodes of different ages showed a second, unexpected pattern (Figure 4). The origin of Niphargus is in northwestern Europe with the MRCA of all Niphargus in what is now central France in the late Cretaceous (88Ma), when Europe consisted of a number of islands (Hay et al. 1999; Rogl 1999). The genus therefore predates (and must have survived) the Cretaceous-Palaeogene mass extinctions of $65 \mathrm{Ma}$ 
371 some of the major palaeogeographical changes that occurred between 100 and $25 \mathrm{Ma}$, 372 although there were smaller scale fluctuations in sea level and uplift superimposed on these broad patterns (Jarvis et al. 2002; Voigt et al. 2006). The ancestor of Niphargus probably colonised a central island (Figure 4c) which was subsequently further inundated by the Tethys Sea (Figure 4d). From there the ancestral locations move with decreasing node age towards the southeast. During the Eocene the retreating Tethys Sea provided the opportunity for Niphargus to spread in emerging freshwater aquifers (Figure 4e). This is consistent with palaeogeographic models but is contrary to a previous hypothesis, which suggested that the enhanced species diversity in the northern parts of the Balkan Peninsula indicated an origin in southeast Europe (Karaman \& Ruffo 1986). Our phylogenetically controlled analysis of diversification rates shows an increase in diversification in a south-easterly direction thereby providing an alternative explanation for the enhanced species diversity in the Balkans. The timing of this diversification (around $25 \mathrm{Ma}$ ) coincides with the closing of the Tethys Sea that had previously separated the Balkans and Central Europe (Hrbek \& Meyer 2003; Rogl 1999) and provided an opportunity for further dispersion towards the south-east (Figure 4f). Available niche space in the geomorphologically complex Balkans may have enabled the high diversification rate; a mechanism which has also been suggested to explain diversification in other fauna (Hrbek \& Meyer 2003).

\section{Conclusions}

This study reveals the presence of an ancient endemic groundwater fauna in the British Isles, where endemism is otherwise rare. The unusually high levels of endemism in groundwater fauna in northern latitudes identified by the study highlights the need to recognise this unique ecosystem and its ancient organisms' contribution to our understanding of climatic and palaeogeographic controls on global biodiversity. The extent to which Niphargus may be resilient to recent anthropogenic perturbations of groundwater ecosystems is unknown. However, the small ranges of these taxa shown in this study and others (Foulquier et al. 2008;

397 Holsinger et al. 1983), and their smaller clutch sizes, delayed maturity, slower growth and lower population numbers compared to epigean relatives (Gibert et al. 1994), suggest that despite their ancient resilience, the European Niphargus fauna could now be vulnerable.

400 Conservation policy measures to protect groundwater ecosystems in Europe lag far behind countries such as Australia. N. glenniei has been designated as a UK Biodiversity Action Plan (BAP) species but other Niphargus species have no such recognition and current European groundwater monitoring programmes do not consider groundwater ecosystems. 
404 The study also reveals an unusual biogeographical pattern within the Niphargus genus. The 405 oldest and most phylogenetically diverse species occur in northern Europe where endemism 406 is low in surface fauna, which are dominated by large range species and post-glacial 407 colonisers. In contrast the species diversity is highest in Southern Europe indicating that once 408 the genus dispersed to these areas, climatic and geomorphological conditions enabled a much 409 higher diversification rate than has occurred in Northern Europe.

410 These groundwater organisms provide an unusual opportunity to improve our understanding 411 of biological processes such as speciation, adaptation and convergence, and as narrow range 412 endemics they allow further exploration of island biogeographical processes. Furthermore, 413 our discovery that these groundwater species are the oldest known inhabitants of Britain and 414 Ireland, persisting through millions of years of changing climate may cast significant light on 415 one of the major challenges facing the scientific community today; that of predicting the 416 resilience of ecosystems to climate change (Chapin et al. 2000). Our findings show that 417 groundwater fauna (or their habitats) are likely to have a highly variable response to the 418 extinguishing effects of climate change. A more detailed knowledge of the mechanisms 419 behind this variation could help us to understand the likely impacts of the current 420 anthropogenically induced challenges to the biosphere.

Acknowledgements For financial support we thank: the EPA Ireland (STRIVE grant, project 2007W-MS-1-S1), the Belgian Science Policy Department (BELSPO), the Linnean Society Systematics Association, the University of Hull, the British Cave Research Association, the British Geological Survey, Roehampton University, and the Esmée Fairbairn Foundation. We thank Thierry Backeljau and Frank Fiers at RBINS, and Bernie Doherty, Ian Anderson, Marlene Jahnke, G.Michel and A.J.Matthijs for technical support. At BGS we thank Andrew Newell for geological advice, Andrew McKenzie for assisting with geographical analyses, Debbie Allen and James Sorensen for sampling. We thank Tim Johns (Environment Agency) and MarieJo Dole-Olivier (Lyon University) for sampling; and Joanna Baker for assistance with the ancestral state reconstruction. We thank Tim Guilford, Mark Pagel, David Lunt and Cock van Oosterhout for useful comments on the manuscript.

Author contributions B.H., G.S.P. A.L.R., and L.M., conceived the study; B.H., C.V., T.M. and A.L.R conducted analyses; C.E.M., B.H. and S.M., carried out laboratory work and 435 assembled the data; C.E.M., S.M, L.R.F.D.K., L.M., A.L.R., J.A., J.S.G.D and K.E collected 
436 the samples and contributed data; B.H., L.M., A.L.R., G.S.P. and C.E.M. wrote the paper; all 437 authors commented on the final draft.

\section{References}

Anderson MP (2005) Heat as a Ground Water Tracer. Groundwater 43, 951-968.

Bohme M (2003) The Miocene Climatic Optimum: evidence from ectothermic vertebrates of Central Europe. Palaeogeography Palaeoclimatology Palaeoecology 195, 389-401.

Bohme M, Ilg A, Winklhofer M (2008) Late Miocene "washhouse" climate in Europe. Earth and Planetary Science Letters 275, 393-401.

Bouckaert R, Lemey P, Dunn M, et al. (2012) Mapping the Origins and Expansion of the IndoEuropean Language Family. Science 337, 957-960.

Boulton GS, Caban PE, Vangijssel K (1995) Groundwater-flow beneth ice sheets. 1. Large-scale patterns. Quaternary Science Reviews 14, 545-562.

Busby J, Kingdon A, Williams J (2011) The measured shallow temperature field in Britain. Quarterly Journal of Engineering Geology and Hydrogeology 44, 373-387.

Chapin FS, Zavaleta ES, Eviner VT, et al. (2000) Consequences of changing biodiversity. Nature 405, 234-242.

Cope JCW (1997) The Mesozoic and Tertiary history of the Irish Sea. In: Petroleum Geology of the Irish Sea and Adjacent Areas (eds. Meadows NS, Trueblood SP, Hardman M, Cowan G), pp. 47-59.

Dole-Olivier M, Castellarini JF, Coineau N, Galassi DMP, Martin P, Mori N, Valdecasas A, Gibert J (2009) Towards an optimal sampling strategy to assess groundwater biodiversity: comparison across six European regions. Freshwater Biology 54, 777-796

Drummond AJ, Ho SYW, Phillips MJ, Rambaut A (2006) Relaxed phylogenetics and dating with confidence. Plos Biology 4, 699-710.

Drummond AJ, Suchard MA, Xie D, Rambaut A (2012) Bayesian Phylogenetics with BEAUti and the BEAST 1.7. Molecular Biology and Evolution 29, 1969-1973.

Dubilier N, Bergin C, Lott C (2008) Symbiotic diversity in marine animals: the art of harnessing chemosynthesis. Nature Reviews Microbiology 6, 725-740.

Dwyer GS, Chandler MA (2009) Mid-Pliocene sea level and continental ice volume based on coupled benthic $\mathrm{Mg} / \mathrm{Ca}$ palaeotemperatures and oxygen isotopes. Philosophical Transactions of the Royal Society a-Mathematical Physical and Engineering Sciences 367, 157-168.

Eberhard SM, Halse SA, Williams MR, et al. (2009) Exploring the relationship between sampling efficiency and short-range endemism for groundwater fauna in the Pilbara region, Western Australia. Freshwater Biology 54, 885-901.

Edgar RC (2004) MUSCLE: multiple sequence alignment with high accuracy and high throughput. Nucleic Acids Research 32, 1792-1797.

Englisch U, Coleman CO, Wagele JW (2003) First observations on the phylogeny of the families Gammaridae, Crangonyctidae, Melitidae, Niphargidae, Megaluropidae and Oedicerotidae (Amphipoda, Crustacea), using small subunit rDNA gene sequences. Journal of Natural History 37, 2461-2486.

Figuera S, Livingstone DM, Hoehn E, Kipfer R (2011) Regime shift in groundwater temperature triggered by Arctic Oscillation. Geophysical Research Letters 38, L23401.

Fišer C, Sket B, Trontelj P (2008) A phylogenetic perspective on 160 years of troubled taxonomy of Niphargus (Crustacea: Amphipoda). Zoologica Scripta 37, 665-680. 
Flot J (2010) Toward a molecular taxonomy of the amphipod genus Niphargus: examples of use of DNA sequences for species identification. Bull Soc Sci Nat Ouest Fr 32, 62-68.

Flot JF, Worheide G, Dattagupta S (2010) Unsuspected diversity of Niphargus amphipods in the chemoautotrophic cave ecosystem of Frasassi, central Italy. Bmc Evolutionary Biology 10.

Foulquier A, Malard F, Lefebure T, Gibert J, Douady CJ (2008) The imprint of Quaternary glaciers on the present-day distribution of the obligate groundwater amphipod Niphargus virei (Niphargidae). Journal of Biogeography 35, 552-564.

Freckleton RP, Phillimore AB, Pagel M (2008) Relating traits to diversification: A simple test. American Naturalist 172, 102-115.

Galassi DMP, Stoch F, Fiasca B, Di Lorenzo T, Gattone E (2009) Groundwater biodiversity patterns in the Lessinian Massif of northern Italy. Freshwater Biology 54, 830-847.

Gibert J, Stanford JA, Dole-Olivier M-J, Ward JV (1994) Basic attributes of groundwater ecosystems and prospects for research. In: Gibert J, Danielopol DL \& Standford JA (eds) Groundwater Ecology. Academic Press, San Diego, CA, 8-42.

Gupta S, Collier JS, Palmer-Felgate A, Potter G (2007) Catastrophic flooding origin of shelf valley systems in the English Channel. Nature 448, 342-U345.

Hänfling B, Douterelo-Soler I, Knight L, Proudlove G (2008) Molecular studies on the Niphargus kochianus group (Crustacea: Amphipoda: Niphargidae) in Great Britain and Ireland. Cave and Karst Science 35, 35-40.

Hartke TR, Fišer C, Hohagen J, et al. (2011) Morphological and molecular analyses of closely related species in the stygobiontic genus Niphargus (Amphipoda). Journal of Crustacean Biology 31, 701-709.

Hay WH, , DeConto RM, et al. (1999) Alternative global Cretaceous paleogeography In: Evolution of the Cretaceous Ocean-Climate System Pages (eds. Barrera E, , Johnson CC), pp. 1-47. Geological Society of America, Boulder, Colorado.

Hewitt GM (2004) Genetic consequences of climatic oscillations in the Quaternary. Philosophical Transactions of the Royal Society of London Series B-Biological Sciences 359, 183-195.

Hof C, Brandle M, Brandl R (2008) Latitudinal variation of diversity in European freshwater animals is not concordant across habitat types. Global Ecology and Biogeography 17, 539-546.

Holsinger JR, Mort JS, Recklies AD (1983) The subterranean crustacean fauna of Castleguard Cave, Colombia icefields, Alberta, Canada, and its zoogeographic significance. Arctic and Alpine Research 15, 543-549.

Hou ZE, Sket B, Fišer C, Li SQ (2011) Eocene habitat shift from saline to freshwater promoted Tethyan amphipod diversification. Proceedings of the National Academy of Sciences of the United States of America 108, 14533-14538.

Hrbek T, Meyer A (2003) Closing of the Tethys Sea and the phylogeny of Eurasian killifishes (Cyprinodontiformes: Cyprinodontidae). Journal of Evolutionary Biology 16, 17-36.

Hutchinson JN, Thomasbetts A (1990) Extent of permafrost in southern Britain in relation to geothermal flux. Quarterly Journal of Engineering Geology 23, 387-390.

Illies J (1978) Limnofauna Europaea, 2nd edn. Gustav Fischer Verlag, Stuttgart.

Jarvis I, Mabrouk A, Moody RTJ, de Cabrera S (2002) Late Cretaceous (Campanian) carbon isotope events, sea-level change and correlation of the Tethyan and Boreal realms. Palaeogeography Palaeoclimatology Palaeoecology 188, 215-248.

Jiang X-W, Wang X-S, Wan L (2010) Semi-empirical equations for the systematic decrease in permeability with depth in porous and fractured media. : . Hydrogeology Journal 18, 839850.

Karaman GS, Ruffo S (1986) Amphipoda: Niphargus group. In: Stygofauna mundi (ed. Botosaneanu L), pp. 514-534. E.J. Brill, Leiden.

Katoh K, Misawa K, Kuma K, Miyata T (2002) MAFFT: a novel method for rapid multiple sequence alignment based on fast Fourier transform. Nucleic Acids Research 30, 3059-3066. 
Klaus S, Gross M (2010) Synopsis of the fossil freshwater crabs of Europe (Brachyura: Potamoidea: Potamidae). Neues Jahrbuch Fur Geologie Und Palaontologie-Abhandlungen 256, 39-59.

Kornobis E, Palsson S, Kristjansson BK, Svavarsson J (2010) Molecular evidence of the survival of subterranean amphipods (Arthropoda) during Ice Age underneath glaciers in Iceland. Molecular Ecology 19, 2516-2530.

Kottelat M, Freyhof J (2007) Handbook of European freshwater fishes. Publications Kottelat.

Lefébure T, Douady CJ, Gouy M, et al. (2006) Phylogeography of a subterranean amphipod reveals cryptic diversity and dynamic evolution in extreme environments. Molecular Ecology 15, 1797-1806.

Lefébure T, Douady CJ, Malard F, Gibert J (2007) Testing dispersal and cryptic diversity in a widely distributed groundwater amphipod (Niphargus rhenorhodanensis). Molecular Phylogenetics and Evolution 42, 676-686.

Lemey P, Rambaut A, Drummond AJ, Suchard MA (2009) Bayesian Phylogeography Finds Its Roots. Plos Computational Biology 5.

Lopez-Garcia P, Philippe H, Gail F, Moreira D (2003) Autochthonous eukaryotic diversity in hydrothermal sediment and experimental microcolonizers at the Mid-Atlantic Ridge. Proceedings of the National Academy of Sciences of the United States of America 100, 697702.

Louwye S, Foubert A, Mertens K, Van Rooij D, Party IES (2008) Integrated stratigraphy and palaeoecology of the lower and Middle Miocene of the Porcupine Basin. Geological Magazine 145, 321-344.

MacDonald AM, Bonsor HC, Ó Dochartaigh BE, Taylor RG (2012) Quantitative maps of groundwater resources in Africa. Environmental Research Letters 7, 024009.

Martin P, De Broyer C, Fiers F, et al. (2009) Biodiversity of Belgian groundwater fauna in relation to environmental conditions. Freshwater Biology 54, 814-829.

Montgomery SH, Capellini I, Barton RA, Mundy NI (2010) Reconstructing the ups and downs of primate brain evolution: implications for adaptive hypotheses and Homo floresiensis. Bmc Biology 8.

Organ CL, Shedlock AM, Meade A, Pagel M, Edwards SV (2007) Origin of avian genome size and structure in non-avian dinosaurs. Nature 446, 180-184.

Pagel M (1999) Inferring the historical patterns of biological evolution. Nature 401, 877-884.

Pagel M, Meade A, Barker D (2004) Bayesian estimation of ancestral character states on phylogenies. Systematic Biology 53, 673-684.

Parsons ML (1970) Groundwater Thermal Regime in a glacial complex. Water Resources Research 6, 1701-1720.

Pimm SL, Russell GJ, Gittleman JL, Brooks TM (1995) The future of biodiversity. Science 269, 347-350.

Provan J, Bennett KD (2008) Phylogeographic insights into cryptic glacial refugia. Trends in Ecology \& Evolution 23, 564-571.

Reid N (2011) European hare (Lepus europaeus) invasion ecology: implication for the conservation of the endemic Irish hare (Lepus timidus hibernicus). Biological Invasions 13, 559-569.

Robertson AL, Smith JWN, Johns T, Proudlove GS (2009) The distribution and diversity of stygobites in Great Britain: an analysis to inform groundwater management. Quarterly Journal of Engineering Geology and Hydrogeology 42, 359-368.

Rogl F (1999) Mediterranean and Paratethys. Facts and hypotheses of an Oligocene to Miocene paleogeography (short overview). Geologica Carpathica 50, 339-349.

Ronquist F, Teslenko M, van der Mark P, et al. (2012) MrBayes 3.2: Efficient Bayesian Phylogenetic Inference and Model Choice Across a Large Model Space. Systematic Biology 61, 539-542.

Summers RW, Dawson RJG, Phillips RE (2007) Assortative mating and patterns of inheritance indicate that the three crossbill taxa in Scotland are species. Journal of Avian Biology 38, 153-162. 
Tamura K, Peterson D, Peterson N, et al. (2011) MEGA5: Molecular Evolutionary Genetics Analysis Using Maximum Likelihood, Evolutionary Distance, and Maximum Parsimony Methods. Molecular Biology and Evolution 28, 2731-2739.

Trontelj P, Blejec A, Fišer C (2012) Ecomorphological convergence pf cave comunities. Evolution 66, 3852-3865.

Trontelj P, Douady CJ, Fišer C, et al. (2009) A molecular test for cryptic diversity in ground water: how large are the ranges of macro-stygobionts? Freshwater Biology 54, 727-744.

Vainola R, Witt JDS, Grabowski M, et al. (2008) Global diversity of amphipods (Amphipoda; Crustacea) in freshwater. Hydrobiologia 595, 241-255.

Van Dover CL, German CR, Speer KG, Parson LM, Vrijenhoek RC (2002) Marine biology - Evolution and biogeography of deep-sea vent and seep invertebrates. Science 295, 1253-1257.

Voigt S, Gale AS, Voigt T (2006) Sea-level change, carbon cycling and palaeoclimate during the Late Cenomanian of northwest Europe; an integrated palaeoenvironmental analysis. Cretaceous Research 27, 836-858.

Weyhenmeyer CE, Burns SJ, Waber HN, et al. (2000) Cool Glacial Temperatures and Changes in Moisture Source Recorded in Oman Groundwaters. Science 287, 842-845.

Wheeler A (1977) The origin and distribution of the freshwater fishes of the British Isles. Journal of Biogeography 4, 1-24.

Williams A, Bloomfield J, Griffiths K, A B (2006) Characterising the vertical variations in hydraulic conductivity within the Chalk aquifer. Journal of Hydrology 330, 53-62.

Williams JR (1970) Ground water in the permafrost regions of Alaska, p. 83. U.S. Geological Survey, Professional Paper 696.

Yalden DW (1982) When did the mammal fauna of the British Isles arrive. Mammal Review 12, 1-57.

Zachos J, Pagani M, Sloan L, Thomas E, Billups K (2001a) Trends, rhythms, and aberrations in global climate 65 Ma to present. Science 292, 686-693.

Zachos JC, Dickens GR, Zeebe RE (2008) An early Cenozoic perspective on greenhouse warming and carbon-cycle dynamics. Nature 451, 279-283.

Zachos JC, Shackleton NJ, Revenaugh JS, Palike H, Flower BP (2001b) Climate response to orbital forcing across the Oligocene-Miocene boundary. Science 292, 274-278.

Supplementary information is available in the online version of the paper. 
614 Tables:

615

616

617

618

619

620

621

622

623

Table 1. A) Estimates of the time of the most recent common ancestor (TMRCA) between British and Irish Niphargus taxa and their closest relatives based on a BEAST analysis. The prior used and mean and median estimates in millions of years (Ma) are given, including the upper and lower bounds of the highest posterior density (HPD) intervals. B) Details of the external calibration points estimated from a subset of representative data from Hou et al. (2011) are given.

\begin{tabular}{|c|c|c|c|c|c|c|}
\hline A) & Node & prior & $\begin{array}{l}\text { Mean } \\
\text { (Ma) }\end{array}$ & $\begin{array}{l}\text { Median } \\
\text { (Ma) }\end{array}$ & $\begin{array}{l}95 \% \text { HPD } \\
\text { lower }\end{array}$ & $\begin{array}{l}\text { 95\% HPD } \\
\text { upper }\end{array}$ \\
\hline & N. aquilex $\mathrm{E} / \mathrm{F}$ & Tree prior & 6.69 & 6.22 & 2.15 & 12.32 \\
\hline & N. aquilex $(\mathrm{A} 1, \mathrm{~A} 2) / \mathrm{B}$ & Tree prior & 5.93 & 5.57 & 2.02 & 10.35 \\
\hline & N. aquilex $\mathrm{A} 1 / \mathrm{A} 2$ & Tree prior & 1.06 & 0.95 & 0.23 & 2.12 \\
\hline & N. fontanus $\mathrm{A} 1 / \mathrm{A} 2$ & Tree prior & 0.89 & 0.77 & 0.17 & 1.90 \\
\hline & N. irlandicus/N. glenniei & Tree prior & 21.05 & 19.48 & 6.74 & 38.09 \\
\hline & N. kochianus $\mathrm{A} /(\mathrm{B}, \mathrm{C})$ & Tree prior & 3.06 & 2.89 & 1.26 & 5.21 \\
\hline & Niphargus root & Uniform [45-558] & 88.16 & 87.14 & 65.38 & 113.94 \\
\hline
\end{tabular}

B) External calibration points from [4]

\begin{tabular}{llllll}
\hline node 1 & Normal $[5.0 ; 1]$ & 5.89 & 5.87 & 4.26 & 7.53 \\
node 2 & Normal $[30.0 ; 1]$ & 29.75 & 29.76 & 27.84 & 31.70 \\
node 3 & Normal $[44.9 ; 8]$ & 47.62 & 47.49 & 35.83 & 59.31 \\
node a & Normal $[80.3 ; 15]$ & 78.52 & 78.19 & 64.87 & 93.26 \\
node b & Normal $[61.3 ; 9]$ & 59.34 & 59.22 & 51.20 & 67.86 \\
node c & Normal $[42.8 ; 6]$ & 44.85 & 44.78 & 39.83 & 50.22 \\
node d & Normal [36; 6] & 32.24 & 32.28 & 26.50 & 37.89 \\
node f & Normal $[25.6 ; 5]$ & 21.67 & 21.79 & 14.14 & 28.93 \\
node g & Normal $[28.2 ; 5]$ & 23.16 & 23.15 & 16.91 & 29.86 \\
node h & Normal [32.9;5] & 33.17 & 33.30 & 25.29 & 40.41 \\
node i & Normal [36.6; 5] & 32.61 & 32.71 & 26.48 & 38.71 \\
\hline
\end{tabular}


626 Figure captions:

627

628

629

630

631

632

633

634

635

636

637

638

639

640

641

642

643

644

645

646

647

648

649

650

651

652

653

654

655

656

657
Figure 1: Distribution of sampling locations from this study and published data included in the analysis

Figure 2: Image of the ancient British endemic Niphargus glenniei, photo credit Chris Proctor (a); multi-gene phylogeny of Niphargus based on a Bayesian analysis (outgroup not shown), posterior probabilities (PP) $>0.5$ of nodes above the clade level are show above branches. See Fig. 3 for PP of nodes within important clades. British and Irish taxa are marked with a red circle and branches leading to them are highlighted red; number in brackets refer to clade numbers in Fig. 3(b) and geographic distribution of major phylogenetic lineages; the exact location of the $N$. liasi sample is not known, but the species occurs in France (c).

Figure 3: Geographic distribution of British and Irish OTU's and European sister taxa. The green and pink lines represent the maximum extent of the glacial ice sheets during the Devensian and Anglian glacial periods respectively. Small black dots are sites of known distribution for each group; coloured dots represent sampled populations for each OTU. Partial ultrametric phylogenies from the BEAST analysis for each species complex are shown above maps. $N$ irlandicus/ $N$ glenniei group (a); N. aquilex/ N. schellenbergi group (b); $N$. kochianus (c), Nfontanus (d).

Figure 4: Time calibrated phylogeny of Niphargus generated with BEAST (outgroup not shown), black dots indicate nodes with a posterior probability $(\mathrm{PP})>0.5$; British and Irish OTUs are marked in red; clade numbers refer to clade numbers in Fig. 2(a); geographic location of the common ancestor for each node with a PP $>0.5$ based on Bayesian model based ancestral state reconstruction; Cricle sizes are proportional to the age of nodes (b); schematic maps depicting some of the major palaeogeographical changes that occurred in Europe between 100 and 25 Ma; modified from Ron Blakey, NAU Geology (http://jan.ucc.nau.edu/rcb7/): $100 \mathrm{Ma}$, circle indicates putative location of Niphargus ancestor (c), 75Ma isolation of Niphargus on a central European island and within the Tethys Sea; the question mark indicates the possibility that the $N$. glenniei/ $N$. irlandicus lineage became first isolated during this time on a north-western European island (d) 50Ma spread of Niphargus across Central Europe (e) 25Ma spread of Niphargus to the Balkan and Italian Penisulas, circle indicates the location of the common ancestor of $N$. irlandicus and $N$. glenniei (f). 


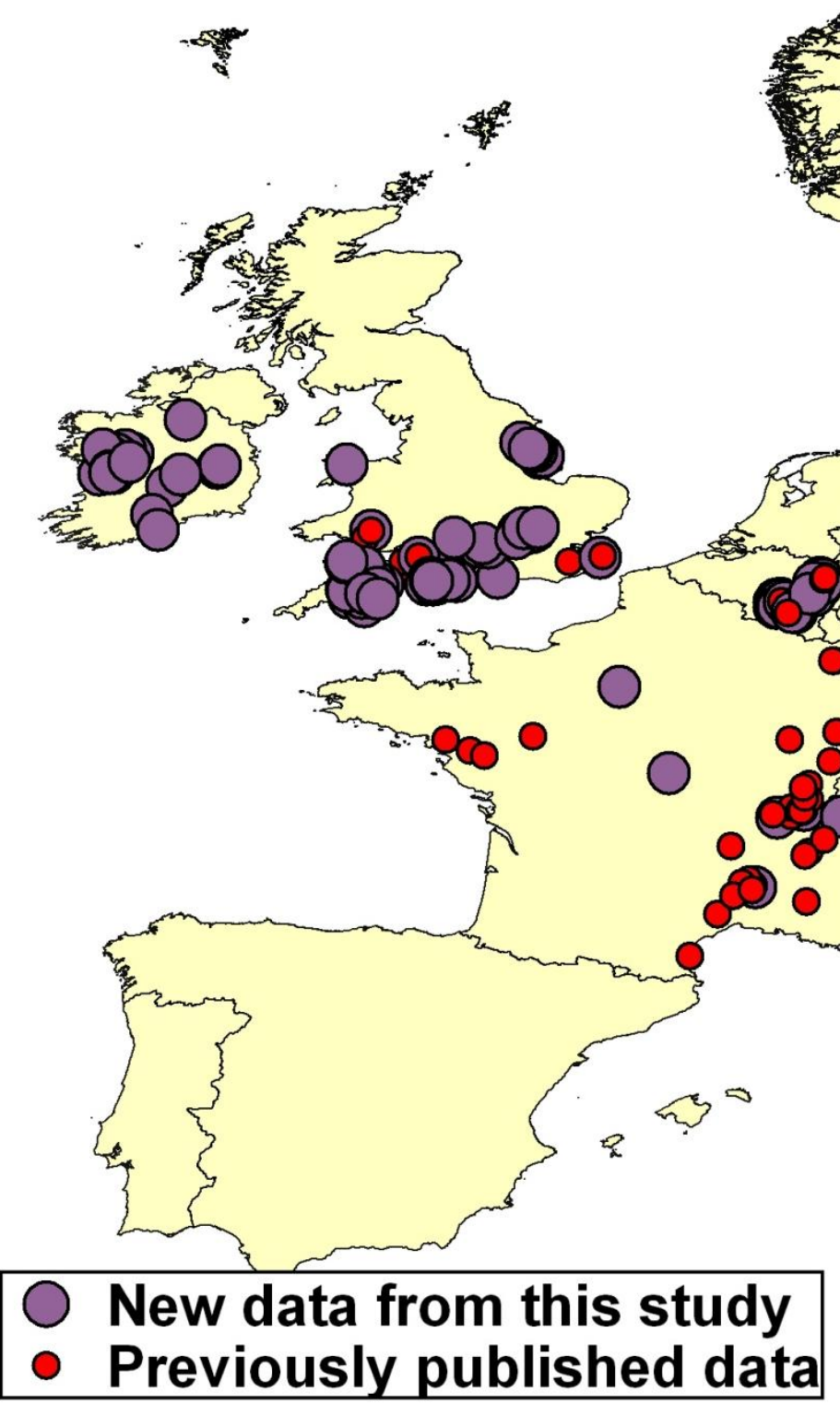


b)

\subsection{0}

1.00

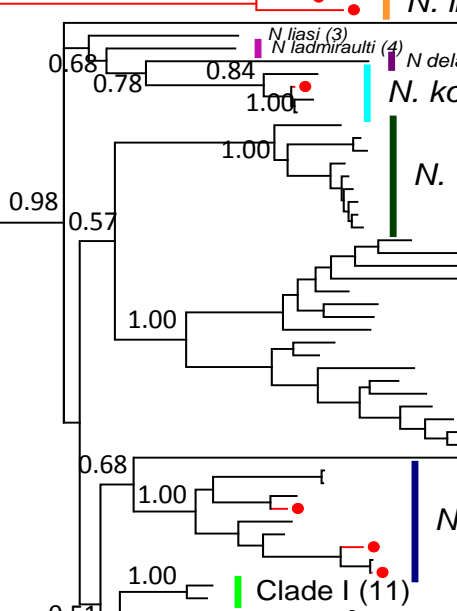

0.51 $1.00 \sqsubset$ | Clade I (11)

N. aquilex/ N schellenbergi (10)
Molecular Ecolo N. kieferi (2)

\section{a)}

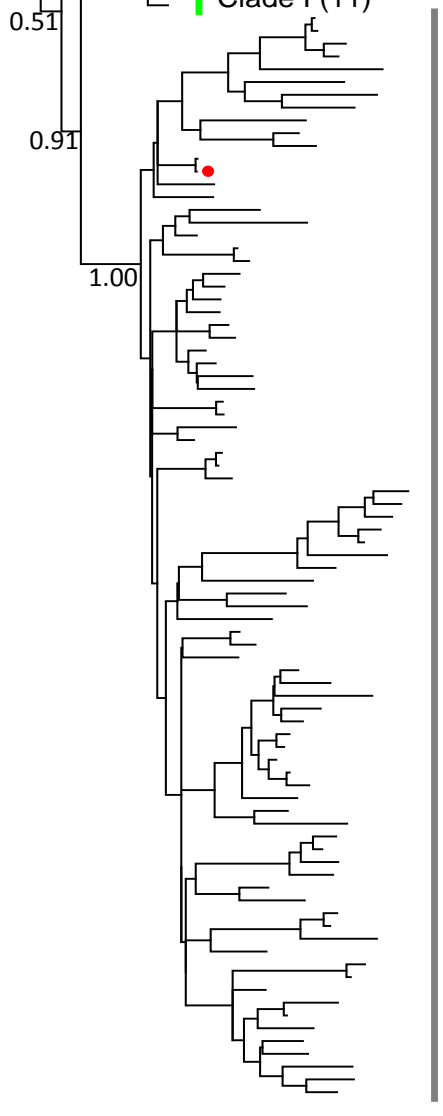

Superclade (12)

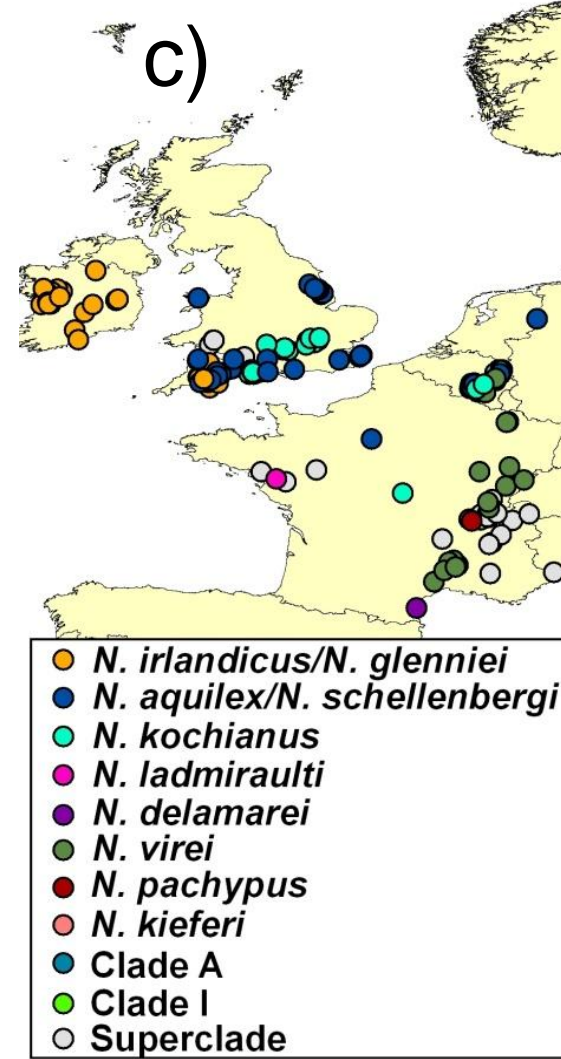

Clade I 


\section{Page 23 of 24}

a)

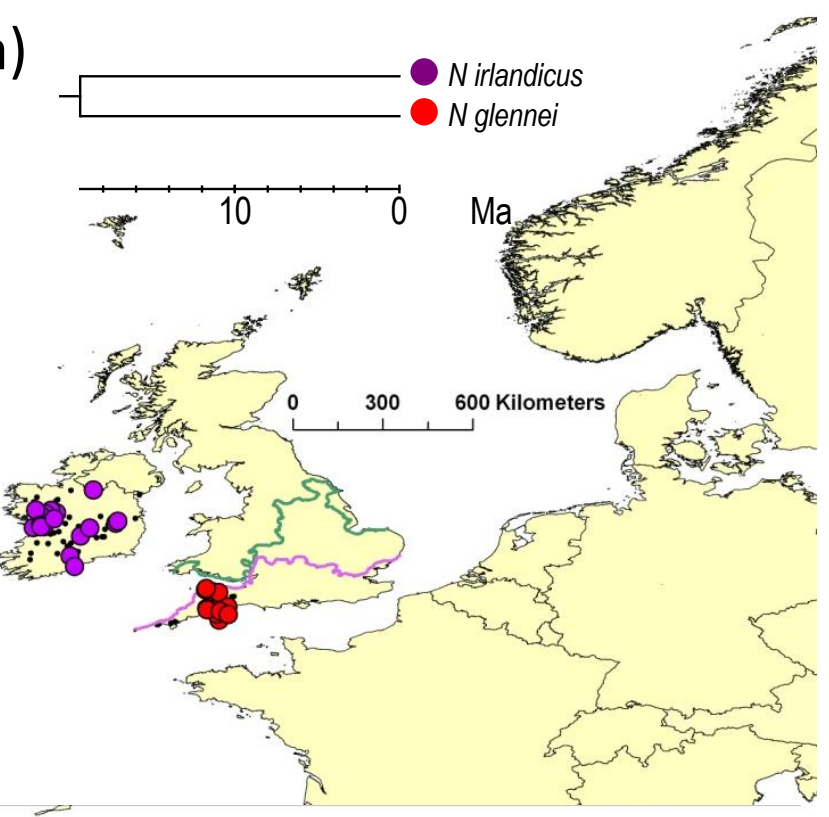

c)
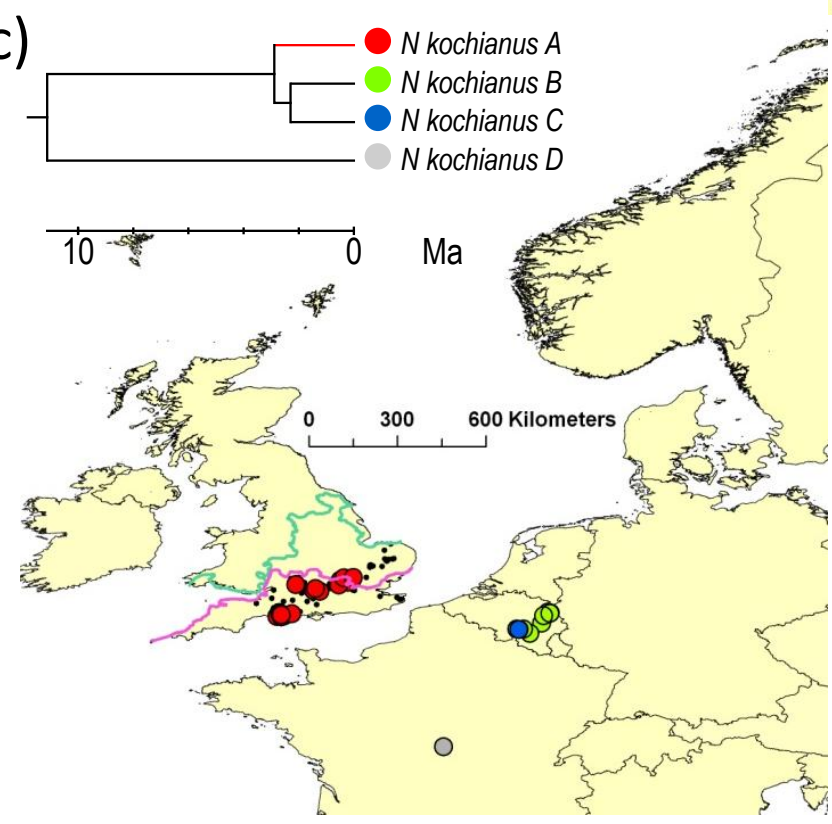

b)

Molecular Ecologivaquilex A1
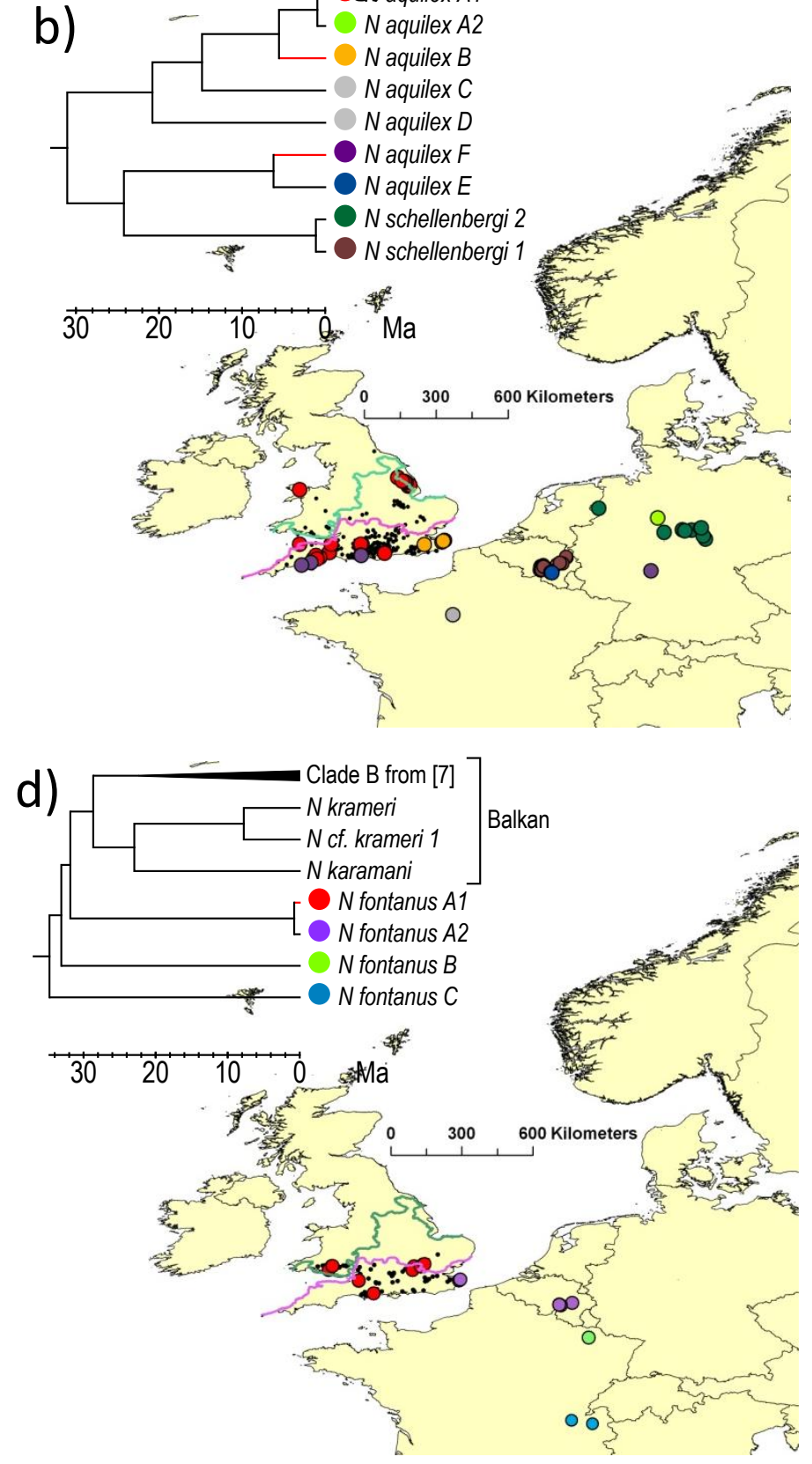
Table 1. A) Estimates of the time of the most recent common ancestor (TMRCA) between British and Irish Niphargus taxa and their closest relatives based on a BEAST analysis. The prior used and mean and median estimates in millions of years (Ma) are given, including the upper and lower bounds of the highest posterior density (HPD) intervals. B) Details of the external calibration points estimated from a subset of representative data from Hou et al. (2011) are given.

\begin{tabular}{|c|c|c|c|c|c|c|}
\hline A) & Node & prior & $\begin{array}{l}\text { Mean } \\
\text { (Ma) }\end{array}$ & $\begin{array}{l}\text { Median } \\
\text { (Ma) }\end{array}$ & $\begin{array}{l}\text { 95\% HPD } \\
\text { lower }\end{array}$ & $\begin{array}{l}\text { 95\% HPD } \\
\text { upper }\end{array}$ \\
\hline & N. aquilex $\mathrm{E} / \mathrm{F}$ & Tree prior & 6.69 & 6.22 & 2.15 & 12.32 \\
\hline & N. aquilex $(\mathrm{A} 1, \mathrm{~A} 2) / \mathrm{B}$ & Tree prior & 5.93 & 5.57 & 2.02 & 10.35 \\
\hline & N. aquilex A1/A2 & Tree prior & 1.06 & 0.95 & 0.23 & 2.12 \\
\hline & N. fontanus A1/A2 & Tree prior & 0.89 & 0.77 & 0.17 & 1.90 \\
\hline & $N$. irlandicus/N. glenniei & Tree prior & 21.05 & 19.48 & 6.74 & 38.09 \\
\hline & N. kochianus $\mathrm{A} /(\mathrm{B}, \mathrm{C})$ & Tree prior & 3.06 & 2.89 & 1.26 & 5.21 \\
\hline & Niphargus root & Uniform [45-558] & 88.16 & 87.14 & 65.38 & 113.94 \\
\hline \multirow[t]{12}{*}{ B) } & \multicolumn{6}{|c|}{ External calibration points from [4] } \\
\hline & node 1 & Normal $[5.0 ; 1]$ & 5.89 & 5.87 & 4.26 & 7.53 \\
\hline & node 2 & Normal $[30.0 ; 1]$ & 29.75 & 29.76 & 27.84 & 31.70 \\
\hline & node 3 & Normal $[44.9 ; 8]$ & 47.62 & 47.49 & 35.83 & 59.31 \\
\hline & node a & Normal $[80.3 ; 15]$ & 78.52 & 78.19 & 64.87 & 93.26 \\
\hline & node $b$ & Normal $[61.3 ; 9]$ & 59.34 & 59.22 & 51.20 & 67.86 \\
\hline & node $\mathrm{c}$ & Normal $[42.8 ; 6]$ & 44.85 & 44.78 & 39.83 & 50.22 \\
\hline & node d & Normal $[36 ; 6]$ & 32.24 & 32.28 & 26.50 & 37.89 \\
\hline & node $f$ & Normal $[25.6 ; 5]$ & 21.67 & 21.79 & 14.14 & 28.93 \\
\hline & node $\mathrm{g}$ & Normal $[28.2 ; 5]$ & 23.16 & 23.15 & 16.91 & 29.86 \\
\hline & node $\mathrm{h}$ & Normal $[32.9 ; 5]$ & 33.17 & 33.30 & 25.29 & 40.41 \\
\hline & node i & Normal $[36.6 ; 5]$ & 32.61 & 32.71 & 26.48 & 38.71 \\
\hline
\end{tabular}

